\title{
Factors Affecting the Degree of Agdression among Students of Indian University
}

\author{
Sunny Sachdeva', Suman Xor², Amarjeet Singh ${ }^{3}$
}

${ }^{1} \mathrm{MPH}$ Postgraduate Student, ${ }^{2}$ Coordinator, Centre for Public Health, Panjab University, Chandigarh.

${ }^{3}$ Professor, Department of Community Medicine, PGIMER, Chandigarh.

DOI: https://doi.org/10.24321/2349.2880.201815

\section{Abstract}

Background: An average of 565 adolescents and young adults between the ages of 10 and 29 year die each day as a result of interpersonal violence across the world. Although a majority of crimes are committed by youth by virtue of their large physical energy along with their aggressive nature.

Objective: To determine the factors affecting the degree of aggression among students of Panjab University, Chandigarh.

Methodology: A sample of 400 students was selected from various departments and Centers of Panjab University. Then from these departments the respondents who were present at the time of the survey were selected by convenient sampling method for the study.

Results: Half of the respondents (58.5\%) lie in mild aggression category of score (58-87), some $(21.7 \%)$ respondents lie in severe aggression category of score (88-145) and (19.8\%) respondents lie in normal aggression category of score (29-57).

Conclusion: Various factors like mother's occupation, family monthly income had significant impact on aggressive behavior of students.

Keywords: Aggression, Dietary habits, Mother's occupation, Parental history Youth

\section{Introduction}

An average of 565 adolescents and young adults between the ages of 10 and 29 year die each day as a result of interpersonal violence across the world. National Family Health Survey 3 (NFHS 3) from India revealed that $27 \%$ married young females experienced physical, sexual, or emotional violence by their spouse and $7 \%$ of all females and $11 \%$ of married females experienced sexual violence. Studies from India reported that $19 \%$ to $42.8 \%$ of adolescent females had experienced domestic violence and $25.3 \%$ and
$32.2 \%$ of young married women experienced physical and sexual violence within marriage, respectively. ${ }^{1}$ Although a majority of crimes are committed by youth by virtue of their large physical energy along with their aggressive nature, there is no separate statistics for age wise segregation of criminals involved in serious crime.

When it comes to the word "YOUTH", we can understand it well by particular age group of people. Conventionally period from adolescence to the middle age is termed as youth. Youth being enthusiastic, vibrant, innovative

Corresponding Author: Sunny Sachdeva, Centre for Public Health, Panjab University, Chandigarh.

E-mail Id: drsunnysachdeva05@gmail.com

Orcid Id: https://orcid.org/0000-0002-8154-4282

How to cite this article: Sachdeva S, Mor S, Singh A. Factors Affecting the Degree of Aggression among Students of Indian University. Ind J Youth Adol Health 2018; 5(3): 17-22. 
and dynamic in nature is the most important section of population. The growth pattern in the youth segment differs substantially from that of general population. The share of youth population in the total population has been increasing continuously from the level of $30.6 \%$ in the year 1971 to $34.8 \%$ in the year 2011. According to the "World Population Prospects: The 2015 Revision ", Population Database of UN Population Division, India has the world's highest number of 10-24 years old with 242 million despite having a smaller population than China, which has 185 million young people. Everyone should take it positively because, a country's ability and potential for growth is determined by size of its youth population. Youth shows strong person, motivation and will power which also make them the most valuable human resource for the fostering economic, cultural and a political development of a nation. ${ }^{2}$ Youth are a source of immense energy and drive. If not harnessed and molded properly this energy not only goes waste, but at times destructive to society. Aggression is a human characteristic necessary for survival in struggle for existence. So, aggression is often used as a defense against dangerous pleasures. Aggression is regarded as a primitive defense originating from "fightflight" response and is frequently deployed when more complex and mature defense fail. Aggression has been noted to have a capacity to bolster the self-esteem by creating an illusion of dominance, strength and control. So, Freud has mentioned, quite early in psychoanalytic literature about use of aggression for defensive purposes. However, it has been witnessed that aggression in youth is said to be increasing. People opine that it is harmful for whole society. So many recent cases can be compiled where youth is indulging in grievous acts like shooting and killing persons as well as animals due to anger; university in and on campus fights for some small issues like during elections, road side fights with either people or with traffic policemen on some vague issues. Data on this aspect is lacking in India.
Therefore, it is important to study the aggression and its related factors among university students.

\section{Methods}

This cross-sectional study was conducted to determine the factors affecting the degree of aggression among students of Panjab University. The study was carried out over the period of January 2018- April 2018. A sample of 400 students was selected from various departments and centers of the University. Departments and centers were identified according to stream of education. Then from these departments the respondents who were present at the time of the survey were selected by convenient sampling method. A semi-structured questionnaire along with Buss and Perry questionnaire was used for collection of data by the researcher. Students who voluntarily signed the written consent were included into the study. Questionnaires were distributed to the students and after briefing them about how to fill it. The collected information of each respondent was entered in Microsoft Excel spreadsheet. Appropriate statistics were applied using SPSS software version 21.

\section{Results}

Among the 400 respondents, 169 (42.2\%) were males and 231 (57.8\%) were females. More than half of participants lie in $18-21$ years age group (54.5\%). Some (33.5\%) of participants were in 21-24 years age group. A few (9.25\%) participants lie in $24-27$ years age group. Some (30\%) of the participants were from nuclear families and many (70\%) participants were from joint families.

Half of the respondents (58.5\%) lie in mild aggression category of score (58-87), some $(21.7 \%)$ respondents lie in severe aggression category of score (88-145) and (19.8\%) respondents lie in normal aggression category of score (29-57).

Table 1.Aggression score of participants according to their mother's occupation

\begin{tabular}{|c|c|c|c|c|}
\hline & \multicolumn{3}{|c|}{ Aggression score } & Total \\
\hline Mother's occupation & Normal (29-57) & Mild (58-87) & Severe (88-145) & $71(17.7)$ \\
\hline Government job & $11(15.5)$ & $43(60.6)$ & $17(23.9)$ & $(19.5)$ \\
& $(13.9)$ & $(18.3)$ & $29(31.9)$ & $91(22.7)$ \\
& $21(23.0)$ & $(43.4)$ & \\
\hline Private job & $(26.5)$ & $(17.6)$ & $41(17.2)$ & $238(59.6)$ \\
& $47(19.7)$ & $150(63.1)$ & $(47.1)$ & 400 \\
\hline House wife & $(59.6)$ & $(64.1)$ & 87 & \\
& 79 & 234 & &
\end{tabular}

Table 1 shows that mother's occupation had significant impact on their children aggression score $\left(\chi^{2}=11.54\right.$ and $p$-value $=0.02$ ). 
Table 2.Aggression score of participants according to their family monthly income

\begin{tabular}{|c|c|c|c|c|}
\hline \multirow[b]{2}{*}{ Family monthly income (Rs.) } & \multicolumn{3}{|c|}{ Aggression score } & \multirow[b]{2}{*}{ Total (\%) } \\
\hline & Normal (29-57) & Mild (58-87) & Severe (88-145) & \\
\hline Less than 50000 & $\begin{array}{c}43(29.2) \\
(54.4)\end{array}$ & $\begin{array}{c}84(57.2) \\
(35.9)\end{array}$ & $\begin{array}{c}20(13.6) \\
(23.0)\end{array}$ & $147(36.8)$ \\
\hline $50000-200000$ & $\begin{array}{c}28(14) \\
(35.4)\end{array}$ & $\begin{array}{c}113(56.5) \\
(48.3)\end{array}$ & $\begin{array}{c}59(29.5) \\
(67.8)\end{array}$ & $200(50)$ \\
\hline More than 200000 & $\begin{array}{c}8(15.1) \\
(10.2)\end{array}$ & $\begin{array}{c}37(69.8) \\
(15.8)\end{array}$ & $\begin{array}{c}8(15.1) \\
(9.2)\end{array}$ & $53(13.2)$ \\
\hline Total & 79 & 234 & 87 & 400 \\
\hline
\end{tabular}

Table 2 shows that effect of monthly income had significant relation with aggression score of participants $\left(\chi^{2}=23.07\right.$ and $p$-value $=0.0001$ ).

Table 3.Aggression score of participants according to their present relationship status

\begin{tabular}{|c|c|c|c|c|}
\hline & \multicolumn{3}{|c|}{ Aggression score } & Severe (88-145) \\
\hline $\begin{array}{c}\text { Present relationship } \\
\text { status }\end{array}$ & Normal (29-57) & Mild (58-87) & Total (\%) \\
\hline Single & $60(23.0)$ & $158(60.5)$ & $43(16.5)$ & $261(65.3)$ \\
& $(75.9)$ & $(67.6)$ & $(49.4)$ & $109(27.3)$ \\
\hline Live-in/committed & $11(10.1)$ & $64(58.7)$ & $(34.2)$ & $30(7.4)$ \\
\hline Break up & $(13.9)$ & $(27.3)$ & $10(33.3)$ & $(11.5)$ \\
\hline
\end{tabular}

Table 3 shows that relationship status had significant effect on aggression score $\left(\chi^{2}=18.86, p\right.$-value $\left.=0.0008\right)$.

Table 4.Aggression score of participants according to their dietary habits

\begin{tabular}{|c|c|c|c|c|}
\hline & \multicolumn{3}{|c|}{ Aggression score } & Total (\%) \\
\hline Dietary habits & Normal (29-57) & Mild (58-87) & Severe (88-145) & $119(29.7)$ \\
\hline Vegetarian & $38(31.9)$ & $65(54.6)$ & $16(13.4)$ & $(18.4)$ \\
\hline Non-vegetarian & $41(14.6)$ & $169(60.2)$ & $71(25.2)$ & $281(70.3)$ \\
& $(51.9)$ & $(72.2)$ & $(81.6)$ & 87.8 \\
\hline
\end{tabular}

Table 4 shows that non-vegetarians had more aggression score than vegetarians $\left(\chi^{2}=18.53, p\right.$-value $\left.=0.000094\right)$.

Table 5.Aggression score of participants according to their habit of sports they were playing

\begin{tabular}{|c|c|c|c|c|}
\hline \multirow[b]{2}{*}{ Type of sports } & \multicolumn{3}{|c|}{ Aggression score } & \multirow[b]{2}{*}{ Total (\%) } \\
\hline & Normal (29-57) & Mild (58-87) & Severe (88-145) & \\
\hline Sports & $\begin{array}{c}36(16.0) \\
(45.5)\end{array}$ & $\begin{array}{c}133(59.1) \\
(56.8)\end{array}$ & $\begin{array}{c}56(24.9) \\
(64.4)\end{array}$ & $225(56.2)$ \\
\hline No Sports & $\begin{array}{c}43(24.6) \\
(54.5)\end{array}$ & $\begin{array}{c}101(57.7) \\
(43.2)\end{array}$ & $\begin{array}{c}31(17.7) \\
(35.6)\end{array}$ & $175(43.8)$ \\
\hline Total & 79 & 234 & 87 & 400 \\
\hline
\end{tabular}

Table 5 shows that type of sports played by participants had significant relation with their aggression score $\left(\chi^{2}=6.024\right.$ and $p$-value $=0.049$ ). 
Table 6.Aggression score of participants according to their alcohol intake

\begin{tabular}{|c|c|c|c|c|}
\hline & \multicolumn{3}{|c|}{ Aggression score } & Total (\%) \\
\hline Alcohol intake & Normal (29-57) & Mild (58-87) & Severe (88-145) & $288(72)$ \\
\hline No & $67(23.2)$ & $173(60.6)$ & $48(16.6)$ & $(55.2)$ \\
& $(84.9)$ & $(73.9)$ & $39(34.8)$ & $112(28)$ \\
\hline Yes & $12(10.7)$ & $61(54.5)$ & $(44.8)$ & 400 \\
\hline
\end{tabular}

Table 6 shows that alcohol intake by the participants and aggression score were dependent variables with significant impact on each other $\left(\chi^{2}=19.08, p\right.$-value $\left.=0.000072\right)$.

Table 7.Aggression score of participants according to their parental history of hypertension

\begin{tabular}{|c|c|c|c|c|}
\hline & \multicolumn{3}{|c|}{ Aggression score } & Severe (88-145) \\
\hline Hypertensive parents & Normal (29-57) & Mild (58-87) & Total (\%) \\
\hline Yes & $23(15.4)$ & $82(55.0)$ & $44(29.5)$ & $149(37.2)$ \\
& $(29.1)$ & $(35.0)$ & $(50.5)$ & $251(62.8)$ \\
\hline No & $56(22.3)$ & $152(60.5)$ & $(17.2)$ & \\
\hline Total & $(70.9)$ & $(65.0)$ & $89.5)$ & 400 \\
\hline
\end{tabular}

Table 7 shows that parental history of hypertension had significant effect on aggression score of participants $\left(\chi^{2}=9.33\right.$ and $p$-value $=0.009$ ).

Table 8.Aggression score of participants according to their parental history of consuming alcohol

\begin{tabular}{|c|c|c|c|c|}
\hline & \multicolumn{3}{|c|}{ Aggression score } & Total (\%) \\
\hline Parent alcoholism & Normal (29-57) & Mild (58-87) & Severe (88-145) & $163(40.7)$ \\
\hline Yes & $24(14.7)$ & $90(55.2)$ & $49(30.1)$ & $(56.3)$ \\
& $(30.4)$ & $(38.5)$ & $38(16.0)$ & $237(59.3)$ \\
\hline No & $55(23.2)$ & $144(60.8)$ & $(43.7)$ & 400 \\
\hline
\end{tabular}

Table 8 shows that participants whose parents were consuming alcohol had more aggression score $\left(\chi^{2}=12.76\right.$ and p-value $=0.001$.

Table 9.Aggression score of participants according to their history of physical/mental abuse

\begin{tabular}{|c|c|c|c|c|}
\hline \multirow[b]{2}{*}{ Physical/ mental abuse } & \multicolumn{3}{|c|}{ Aggression score } & \multirow[b]{2}{*}{ Total (\%) } \\
\hline & Normal (29-57) & Mild (58-87) & Severe (88-145) & \\
\hline No & $\begin{array}{c}66(21.2) \\
(83.5)\end{array}$ & $\begin{array}{c}186(59.8) \\
(79.4)\end{array}$ & $\begin{array}{c}59(18.6) \\
(67.4)\end{array}$ & $311(77.8)$ \\
\hline Yes & $\begin{array}{c}13(14.6) \\
(16.4)\end{array}$ & $\begin{array}{c}48(53.9) \\
(20.5)\end{array}$ & $\begin{array}{c}28(31.4) \\
(32.5)\end{array}$ & $89(22.2)$ \\
\hline Total & 79 & 234 & 87 & 400 \\
\hline
\end{tabular}

Table 9 shows that there was significant relation between history of physical or mental abuse and aggression score $\left(\chi^{2}\right.$ $=6.90, \mathrm{p}$-value $=0.031$ ). 
Table 10.Aggression score of participants according to their part of any political organization

\begin{tabular}{|c|c|c|c|}
\hline & \multicolumn{2}{|c|}{ Aggression } & Total (\%) \\
\hline Member of political organization & No & Yes & $308(77)$ \\
\hline No & $68(22.1)$ & $(70(77.9)$ & $(74.8)$ \\
\hline Yes & $11(11.9)$ & $81(88.1)$ & $92(23)$ \\
\hline Total & $(13.9)$ & 321 & 400 \\
\hline
\end{tabular}

Table 10 shows that there was significant relation between aggression score and participant history of joining of any political organization $\left(\chi^{2}=4.57, p\right.$-value $\left.=0.032\right)$.

\section{Discussion}

Overall prevalence of aggression to be $80.2 \%$ which is higher than the study conducted by Garg I et al. in 2008. ${ }^{3}$ It means every 4 in 5 individuals had some or more aggression with one fifth having severe aggression. Such a high prevalence indicates that it is a serious public health issue. A significant relation was found between aggression score and mother's occupation Similar findings were reported by Garg I et al. ${ }^{3}$ Participants with working mothers were more aggressive similarly who were in relationship were more aggressive. It may be because they tried to fill their emptiness of motherly affection with other relationships. There are various factors which might have promote this romantic relationship behavior in these children like less time are given by working women to their children, less supervision by them of their children's whole day activities and presence of electronic gadgets which make easier to connect with other people.

This study showed significant relation between socialeconomic status and degree of aggression in respondents. One probable explanation of this finding might be related with the domain-specific theory of self-esteem (Rosenberg, 1965; Rubin and Hewstone, 1998; Baumeister, 1998; Kirkpatrick et al., 2002). This theory states that functionally distinct domains of self-esteem would predict aggression differentially. It is, perhaps, important to note that SES may be regarded as functionally distinct domains of selfesteem. The persons with high SES perceive themselves to be superior too often. The persons with low SES, on other hand, perceive social exclusion. Thus, social superiority and social exclusion emerged as reliable and positive predictor of hostile aggression (Baumeister and Boden, 1998; Bushman and Baumeister, 1998). The findings of the present study may be approached from the view-point of these theoretical perspectives. In past same type of study conducted by Rahman AKMR, Huq MM and they also stated that there was significant relation between family income and degree of aggression in participants. ${ }^{4}$ Many have assumed that the relation of money to politics is like a law of Nature: the more money one has, the more political power one can wield. Within the system of capitalism, the more money and power one has, the easier it is to acquire still more money and power.

Prevalence of severe aggression was significantly more (29.3\%) in participants that had joined political organization or those who were part of any political organization.

There is a popular perception that vegetarians are less aggressive than non-vegetarians although it has not been supported by any reliable observational or empirical evidence. Data from the present study indicate that participants from non-vegetarian families, who consume meat with their diets, are on the average more aggressive than vegetarians. Same type of study done by Jain et al and they found prevalence of high aggressiveness among omnivores as compared to vegetarians. ${ }^{5}$ Present study found that prevalence of high aggressiveness among nonvegetarians was estimated to be $29.5 \%$ as against $13.4 \%$ in vegetarians $(P<0.001)$. Present results, which are statistically highly significant, provide support to an association between aggressiveness and consumption of meat. This initial epidemiological evidence, if confirmed by more comprehensive and holistic cross-cultural investigations, could have important implications for personal lifestyle, public health, and also for basic research in nutritional and behavioral sciences.

Alcohol also increases aggression (Bushman, 1993). These effects appear to be indirect rather than direct; Bushman (1997) found that aggression-facilitating factors (e.g. provocation, frustration, aggressive cues) have a much stronger effect on people who are under the influence of alcohol than on people who are not. There are several possible explanations for why alcohol increases aggression. One explanation is that alcohol reduces inhibitions. Normally people have strong inhibitions against behaving aggressively, and alcohol reduces these inhibitions. A second explanation is that alcohol creates a "myopic" or narrowing effect on attention. A third explanation is that alcohol increases aggression by decreasing self awareness. A fourth explanation is that alcohol disrupts executive functions, which are cognitive abilities that help us plan, organize, reason, achieve goals, control emotions, 
and inhibit behavior tendencies. ${ }^{5}$ Sharma MK, Marimuthu $P$ conducted a study correlates of aggression among youth and found that there was a significant relation in the subjects who consume substance and the level of aggression in them. The subjects who consumed substance abuse had a high score on aggression when compared with the non-substance abuser. ${ }^{6}$ Present study also suggested that there was significant increase in aggression score of participants who took alcohol as compared to those who did not (84.3\%).

In sports, aggression is a characteristic that can have many negative as well as positive effects on performance. Most people view aggression as a negative psychological characteristic; however, some sport psychologists agree that aggression can improve performance (Widmeyer \& Birch, 1984). This is called an assertive behavior (Bredemeier, 1994), where a player will play within the rules of the sport at a very high intensity but will have no intention to harm an opponent. Present study shows that prevalence of severe aggression was more in participants who played games $(24.9 \%)$ as compared to those who did not play any game. Reason for this was high stamina and energy in players as compared to non-players.

This study shows that aggression score was more in participants who had history of parental hypertension (29.5\%) and parental alcoholism (30.1\%) as compared to those who had not such history. Guilt is common for a young child to feel as they witness their parent using alcohol. Children have a tendency to blame themselves for their parent's drinking. They may feel that their parent does this as a reaction to their bad behavior. Children who had exposed to abuse and neglect are at increased risk of inflicting pain on others and developing aggressive and violent behaviors' in adolescence (Gilbert et al., 2009; Haapasalo and Pokela, 1999; Maas, Herrenkohl and Sousa, 2008; Trickett et al., 2011). ${ }^{7}$ Research suggests that physical abuse and exposure to family violence are the most consistent predictors of youth violence (Gilbert et al., 2009; Maas et al., 2008). ${ }^{7}$ In a meta-analysis by Gilbert et al., both prospective and retrospective studies indicated strong associations between child abuse and neglect and criminal behavior. ${ }^{7}$ A National Institute of Justice study in the US predicted that abused and neglected children were 11 times more likely to be arrested for criminal behavior in adolescence (English, Widom and Brandford, 2004). ${ }^{7}$ From the present study we can conclude that participants who had history of physical or mental abuse had showed more aggression (31.4\%) in comparison to those who did not have such history.

\section{Conclusion}

A high prevalence of severe aggression was noticed among students of Panjab University Chandigarh. Many factors had a significant association with aggressive behavior of participants in the study e.g. mother's employment, higher family income, present relationship status, non-vegetarian dietary habits, frequency of consuming non-vegetarian diet, type of sports they played, alcohol drinking habit, history of physical/mental abuse, membership of political organization, parental history of hypertension, parental history of alcohol consumption.

Collected data was based on self-reporting. Under or over reporting of behavior might had affected the results. Due to social stigma many students might had hidden the real facts and their feelings.

Programs like mentorships as seen in western countries should include students counseling in university (i.e. at rise approach) based on our results.

\section{Conflict of Interest: None}

\section{References}

1. Singh S, Gopalkrishna G. Health behaviors' and problems among young people in India: cause for concern and call for action. Indian J Med Res 2014; 140: 185-208.

2. United Nations organization. World population ageing. Available from: www.un.org/en/development/desa/ population/publications/.../WPA2015. Accessed on May 30, 2018.

3. Garg I, Sethi S, Kishore J. The prevalence and patterns of aggression in school adolescents in a rural area of Moga district of Punjab, India. Indian J of Youth Adolescent Health 2018; 5(1): 43-6.

4. Rahman AKMR, Huq MM. Aggression in adolescent boys and girls as related to socio-economic status and residential background. J Life Earth Science 2005; 1(1): 5-9.

5. Jain K, Sharma S, Prajna SC, et al. Influences of gender, religion, dietary patterns, and mixed-sex education on aggressiveness in children: a socio demographic study in municipal primary schools. Indian J of Public Health 2018; 62(1): 21-6.

6. Sharma MK, Marimuthu P. Prevalence and psychosocial factors of aggression among youth. Indian $J$ of Psychological Medicine 2014; 36(1): 48-53.

7. Australian Institute of Family Studies. Effects of child abuse and neglect for children and adolescents. Available from: https://aifs.gov.au/cfca/publications/ effects-child-abuse-and-neglect-children-andadolescents.CFCA2014. Accessed on: May 30, 2018.

Date of Submission: 2018-06-o8 Date of Acceptance: 2018-06-22 